Supporting Information

\title{
Implications of the Differential Toxicological Effects of III-V Ionic and Particulate Materials for Hazard Assessment of Semiconductor Slurries
}

Wen Jiang, ${ }^{\dagger}$ Sijie Lin, ${ }^{\dagger}$ Chong Hyun Chang, ${ }^{\dagger}$ Zhaoxia $\mathrm{Ji}^{\dagger}{ }^{\dagger}$ Bingbing Sun, ${ }^{\dagger}$ Xiang Wang, ${ }^{\dagger}$ Ruibin Li, ${ }^{\dagger}$ Nanetta Pon, ${ }^{\dagger}$ Tian Xia, ${ }^{\dagger, \ddagger}$ and André E. Nel ${ }^{\star, t, \neq}$

${ }^{\dagger}$ Center for Environmental Implications of Nanotechnology, California NanoSystems Institute, University of California Los Angeles, 570 Westwood Plaza, Los Angeles, CA 90095, United States and Division of NanoMedicine, Department of Medicine, University of California Los Angeles, 10833 Le Conte Ave, Los Angeles, CA 90095, United States

*Address correspondence to anel@mednet.ucla.edu. 
Table S1. Elemental analysis of III-V particulates by ICP-OES.

\begin{tabular}{llll}
\hline \multirow{2}{*}{ NPs } & \multicolumn{3}{c}{ Average (wt. \%) } \\
\cline { 2 - 4 } Fe & Ca & Mg \\
\hline m-GaP & $2.50 \pm 0.27$ & $0.79 \pm 0.02$ & $0.11 \pm 0.01$ \\
m-GaAs & $5.52 \pm 0.16$ & $0.80 \pm 0.10$ & $0.13 \pm 0.01$ \\
m-InP & $4.03 \pm 0.08$ & $0.84 \pm 0.03$ & $0.15 \pm 0.02$ \\
m-InAs & $5.53 \pm 0.07$ & $0.79 \pm 0.08$ & $0.11 \pm 0.01$ \\
n-GaP & $2.70 \pm 0.03$ & $0.81 \pm 0.05$ & $0.11 \pm 0.01$ \\
n-GaAs & $3.87 \pm 0.08$ & $0.77 \pm 0.03$ & $0.11 \pm 0.01$ \\
n-InP & $1.96 \pm 0.02$ & $0.95 \pm 0.15$ & $0.12 \pm 0.01$ \\
n-InAs & $3.04 \pm 0.06$ & $0.74 \pm 0.08$ & $0.15 \pm 0.04$ \\
\hline
\end{tabular}


Table S2. Calculation of the molar concentration based on the mass concentration of III-V materials.

\begin{tabular}{ccc}
\hline Sample & Molar mass $(\mathbf{g} / \mathbf{m o l})$ & $\begin{array}{c}\text { Molar concentration recalculation } \\
(\boldsymbol{\mu m o l} / \mathbf{m L})^{\mathbf{a}}\end{array}$ \\
\hline $\mathrm{m}-\mathrm{GaP} / \mathrm{n}-\mathrm{GaP}$ & 100.70 & $0.125-1$ \\
$\mathrm{~m}-\mathrm{GaAs} / \mathrm{n}-\mathrm{GaAs}$ & 144.65 & $0.09-0.70$ \\
$\mathrm{~m}-\mathrm{InP} / \mathrm{n}-\mathrm{InP}$ & 145.79 & $0.09-0.69$ \\
$\mathrm{~m}-\mathrm{InAs} / \mathrm{n}-\mathrm{InAs}$ & 189.74 & $0.07-0.52$ \\
$\mathrm{GaCl}_{3}$ & 176.08 & $0.07-0.56$ \\
$\mathrm{InCl}_{3}$ & 221.18 & $0.06-0.45$ \\
$\mathrm{Na}_{2} \mathrm{HAsO}_{4} \bullet \mathrm{H}_{2} \mathrm{O}$ & 312.01 & $0.04-0.32$ \\
$\mathrm{ZnO}$ & 81.41 & $0.153-1.22$
\end{tabular}

${ }^{a}$ Molar concentration was calculated based on material mass concentrations, ranging from 12.5$100 \mu \mathrm{g} / \mathrm{mL}$. The final molar concentration for GaAs in Figure 2 is $0.07-0.7 \mu \mathrm{mol} / \mathrm{mL}$, which is equivalent to $12.5-100 \mu \mathrm{g} / \mathrm{mL}$. 

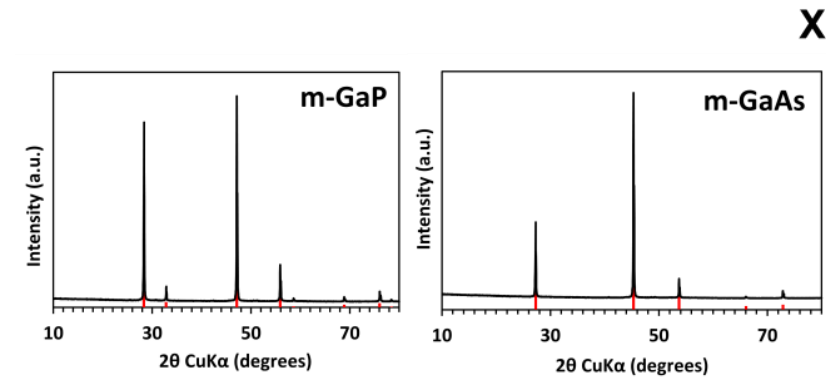

XRD
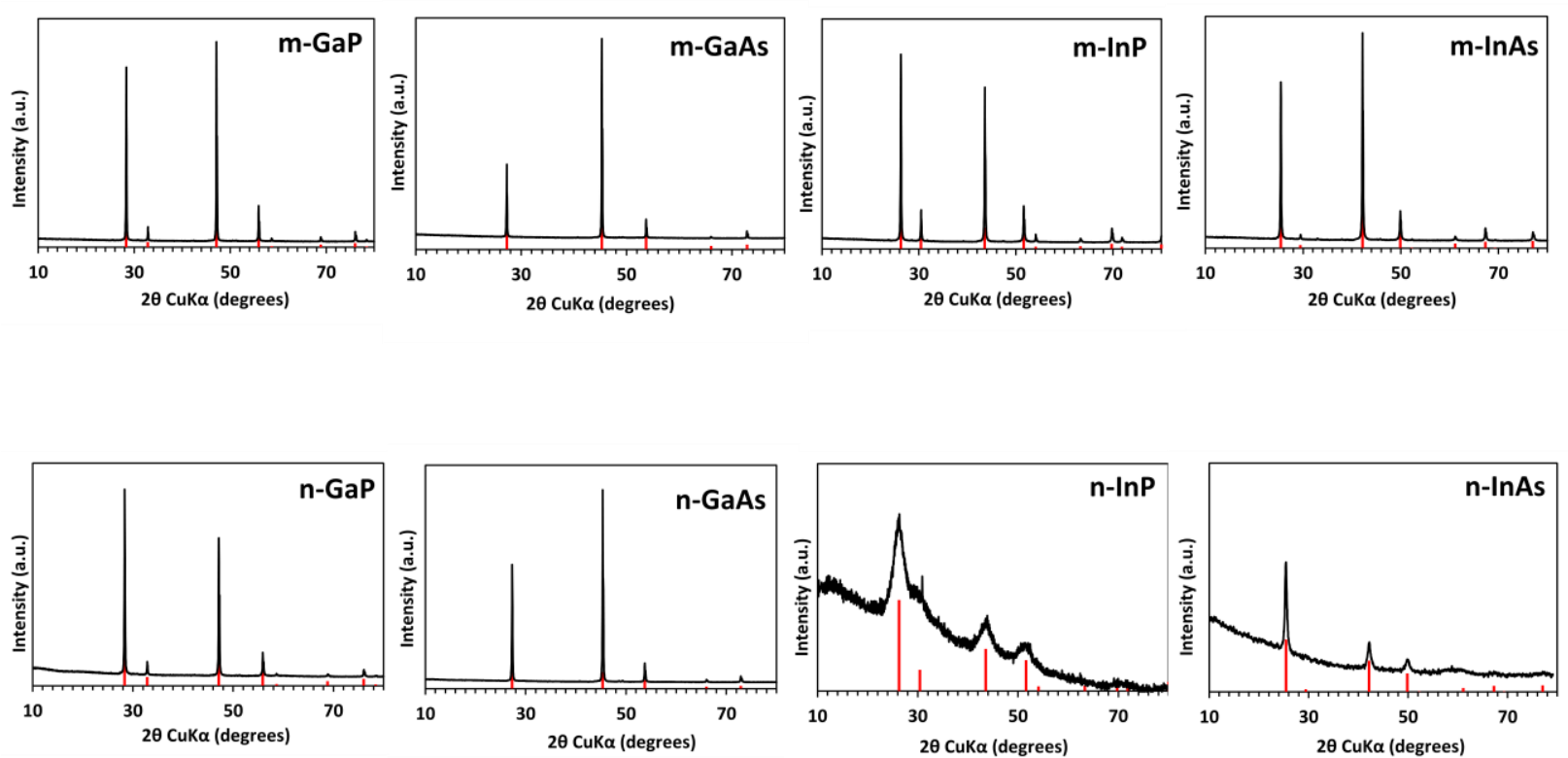

Figure S1. X-ray diffraction (XRD) analysis of III-V particles. The XRD patterns were collected in a Panalytical X'Pert Pro diffractometer ( $\mathrm{Cu} \mathrm{K} \alpha$ radiation), with a step size of $0.02^{\circ}$ and a counting time of $0.5 \mathrm{~s}$ per step over a range of $10-80^{\circ} 2 \theta$. 
A

THP-1: CellTox ${ }^{\mathrm{TM}}$ assay

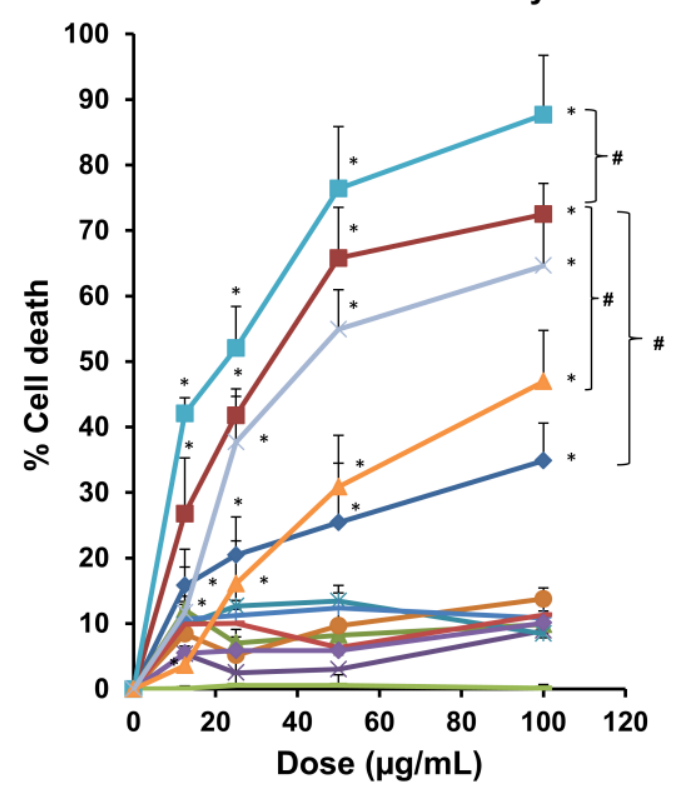

C

BEAS-2B: CellTox ${ }^{\mathrm{TM}}$ assay

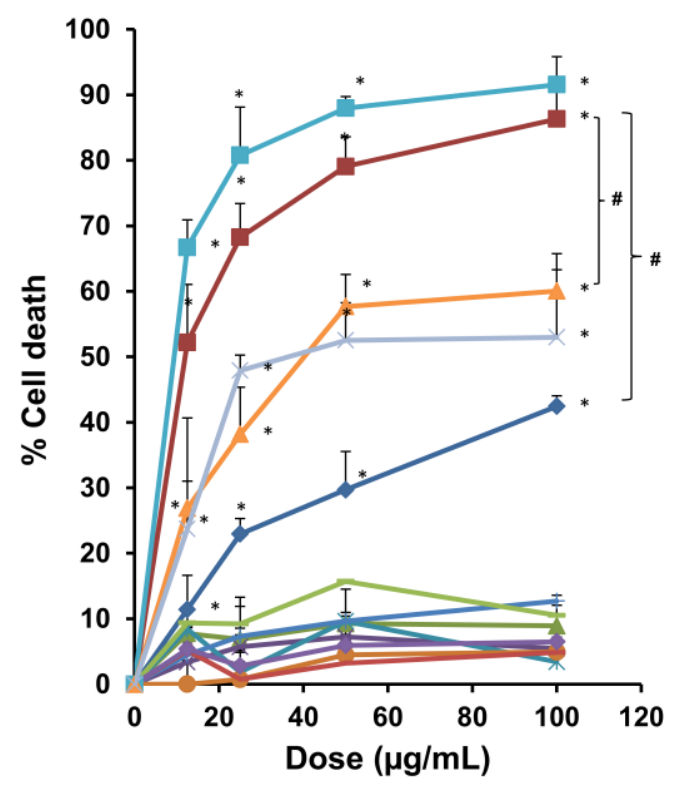

B

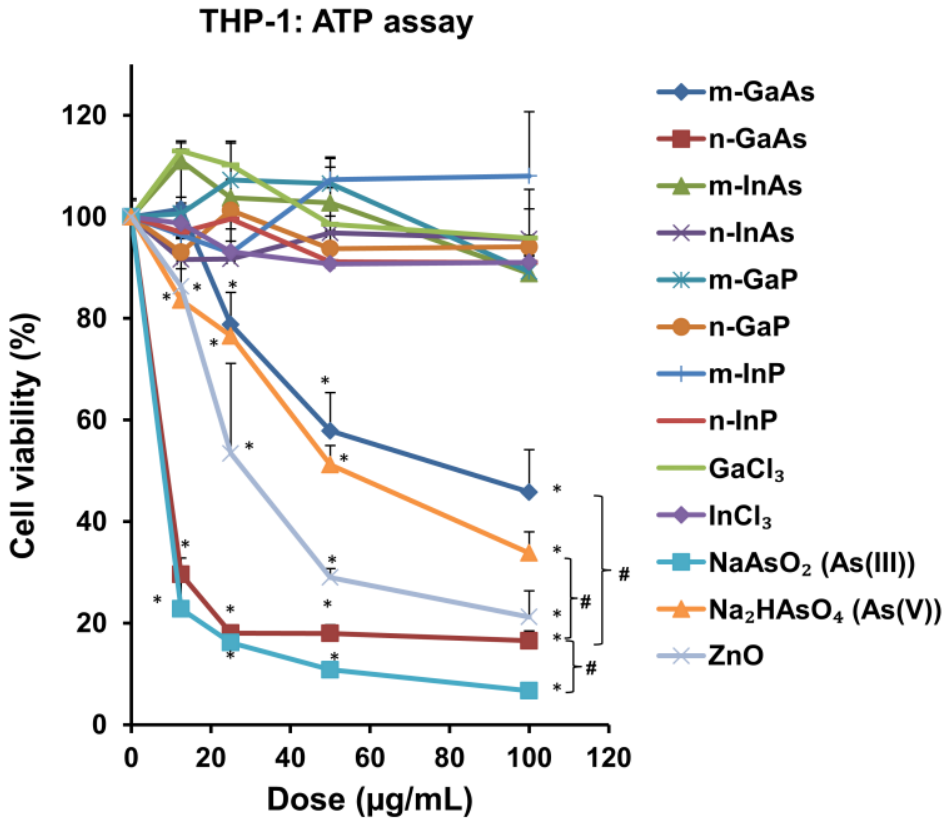

D

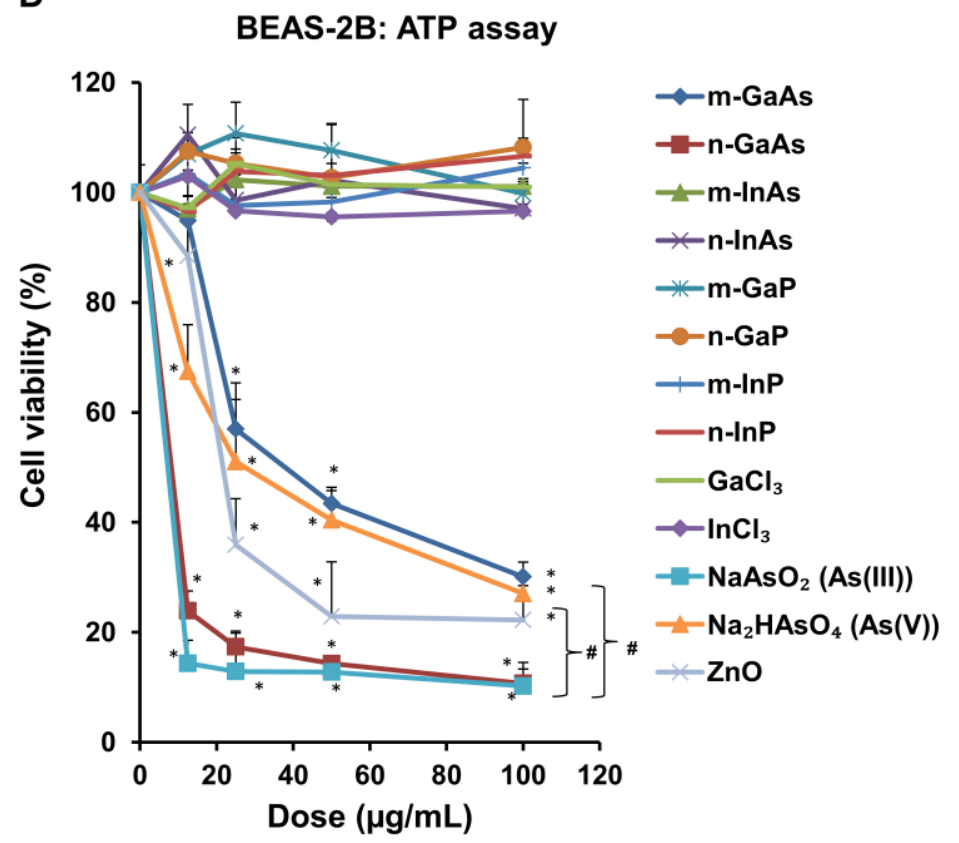

Figure S2. III-V material toxicity in THP-1 and BEAS-2B cells plotted by mass dose. Particles and salts, suspended in cell culture medium at 12.5-100 $\mu \mathrm{g} / \mathrm{mL}$, were used to expose THP-1 and BEAS-2B cells for $24 \mathrm{~h}$. (A) Assessment of THP-1 cell death by the CellTox ${ }^{\mathrm{TM}}$ Assay. (B) Assessment of THP-1 viability using the ATP assay. (C) Assessment of BEAS-2B cell death by the CellTox ${ }^{\mathrm{TM}}$ Assay. (D) Assessment of BEAS-2B viability by the ATP assay. (*) $\mathrm{p}<0.05$ compared to control; (\#) $\mathrm{p}<0.05$, comparing with $\mathrm{n}$-GaAs. 

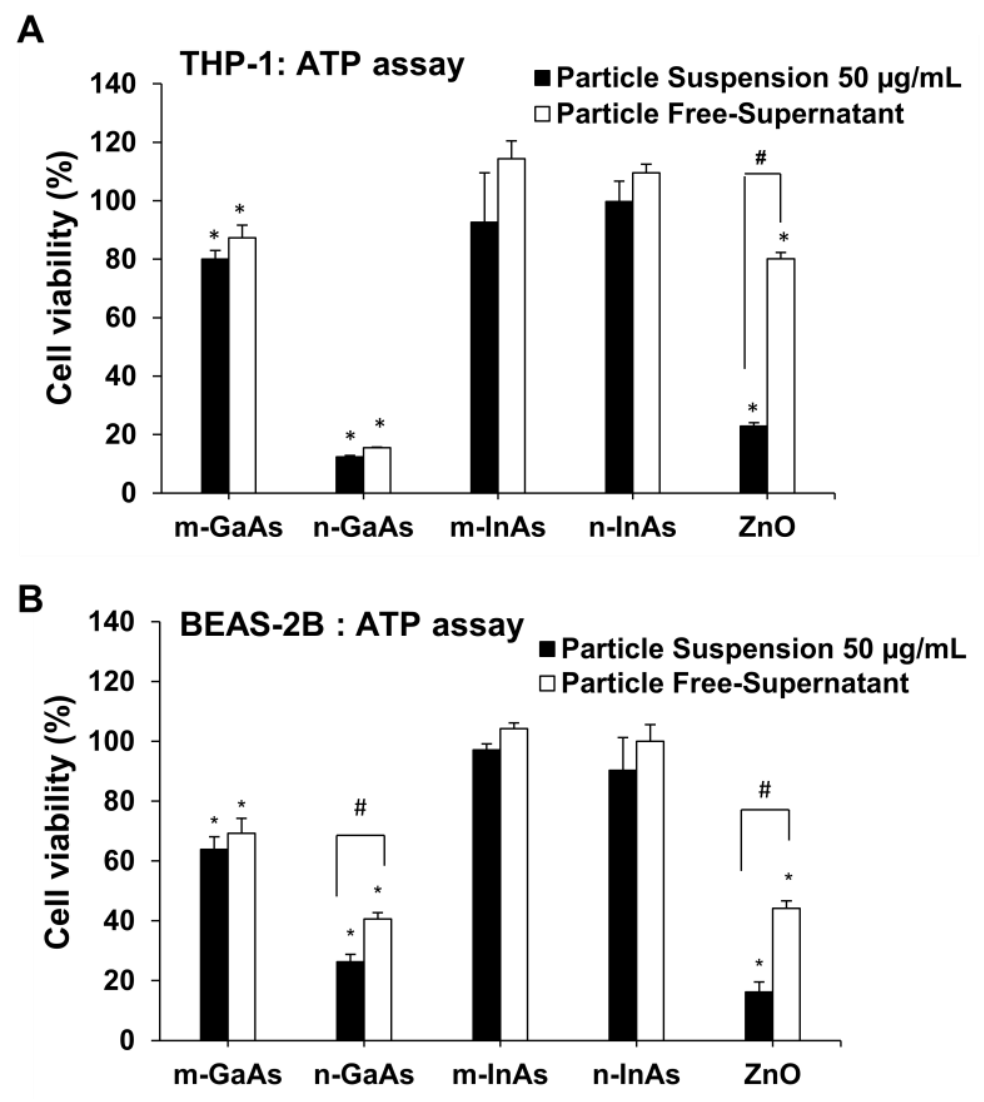

Figure S3. An ATP assay was used to determine THP-1 (A) and BEAS-2B (B) cell viability after incubation with $50 \mu \mathrm{g} / \mathrm{mL} \mathrm{GaAs}$ and InAs particle suspensions or the corresponding particle free supernatants. The supernatants were collected following the centrifugation of RPMI (10\% FBS), and BEGM ( $2 \mathrm{mg} / \mathrm{mL}$ BSA) particle suspensions after the incubation in $50 \mu \mathrm{g} / \mathrm{mL}$ particles for $24 \mathrm{~h}$. $100 \mu \mathrm{l}$ of each supernatant was added to $3 \times 10^{4}$ THP- 1 cells or $2 \times 10^{4}$ BEAS-2B cells in each well of CostarTM 96-well plates. (*) $\mathrm{p}<0.05$ compared to control. (\#) $\mathrm{p}<0.05$. 
A
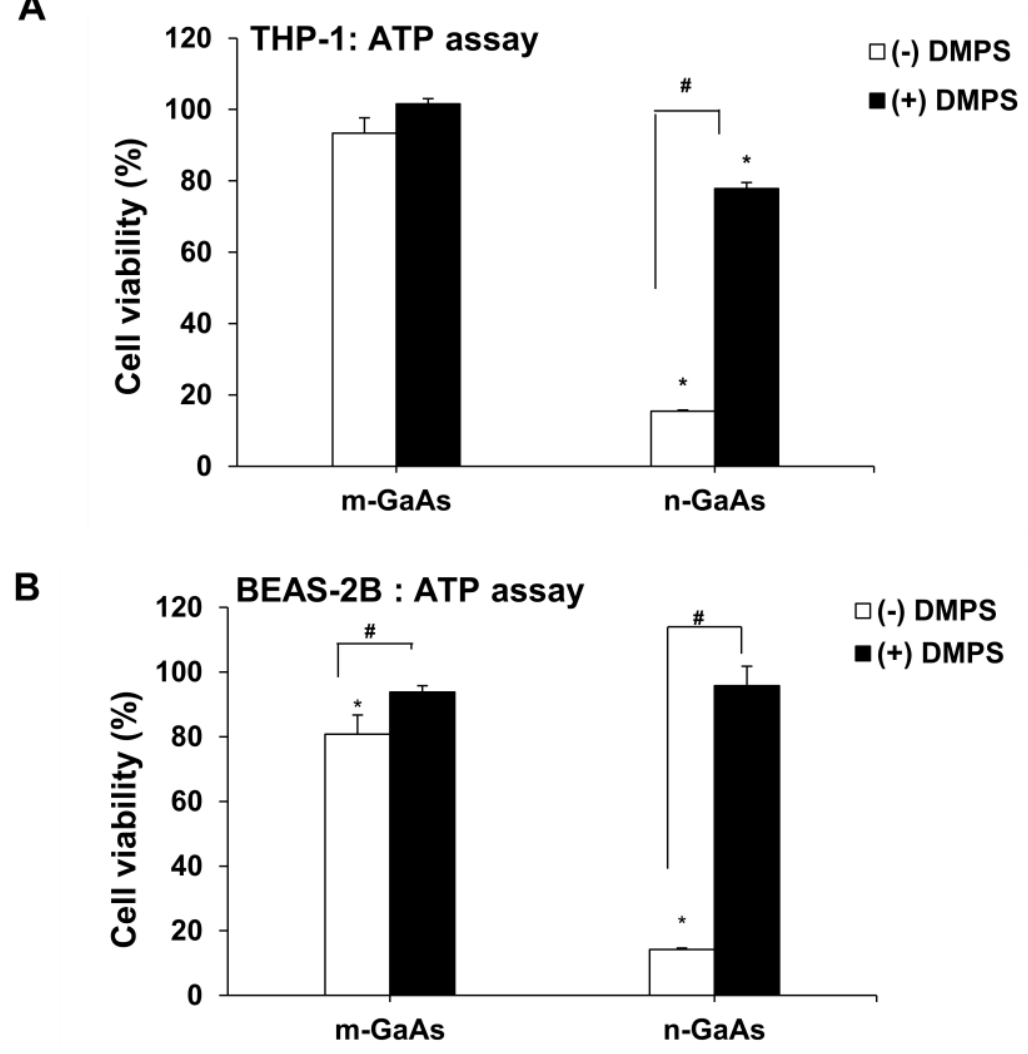

Figure S4. (A) THP-1 and (B) BEAS-2B cell viability (ATP assay) in the presence or absence of $0.35 \mu \mathrm{mol} / \mathrm{mL}$ DMPS added to the supernatant from micron- or nano-scale GaAs suspensions, generated as described in Figure 3E and 3F. (*) p $<0.05$ compared to control; (\#) $p<0.05$. 


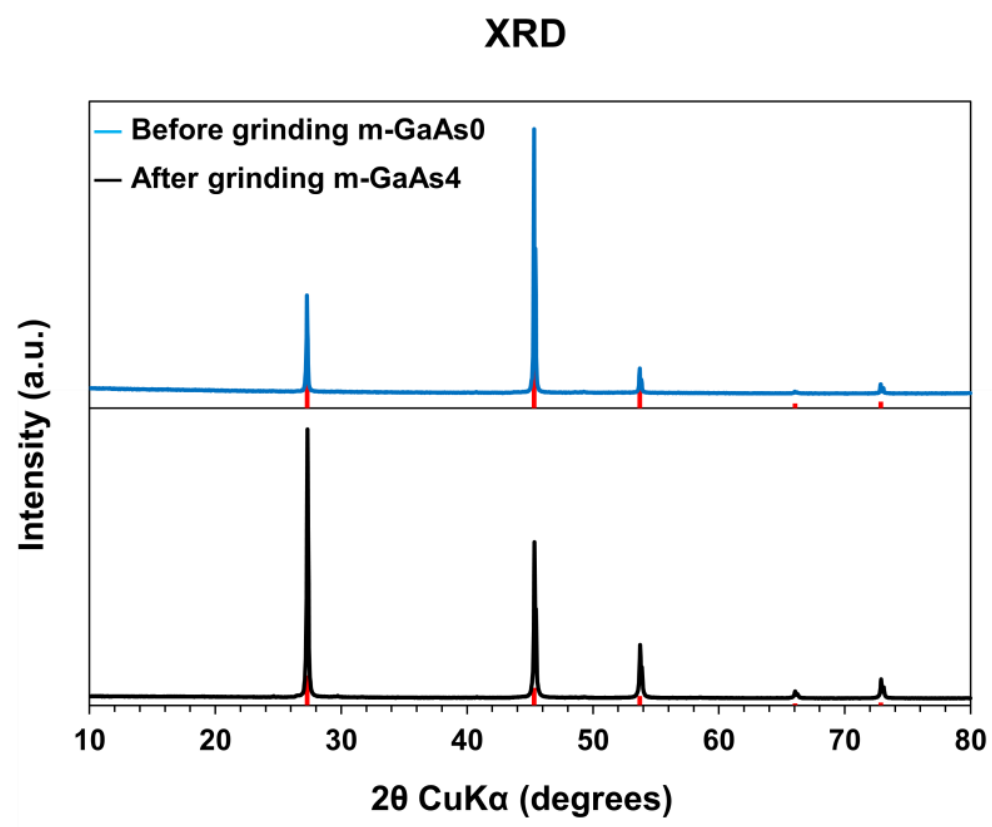

Figure S5. XRD analysis of micon-sized GaAs particles before (m-GaAs0) and after (m-GaAs4) pulverization as described in Figure 4A. Particles $\mathrm{m}-\mathrm{GaAs} 4$ were generated by grinding of $\mathrm{m}-$ GaAs0 for $2 \mathrm{~h}$. 


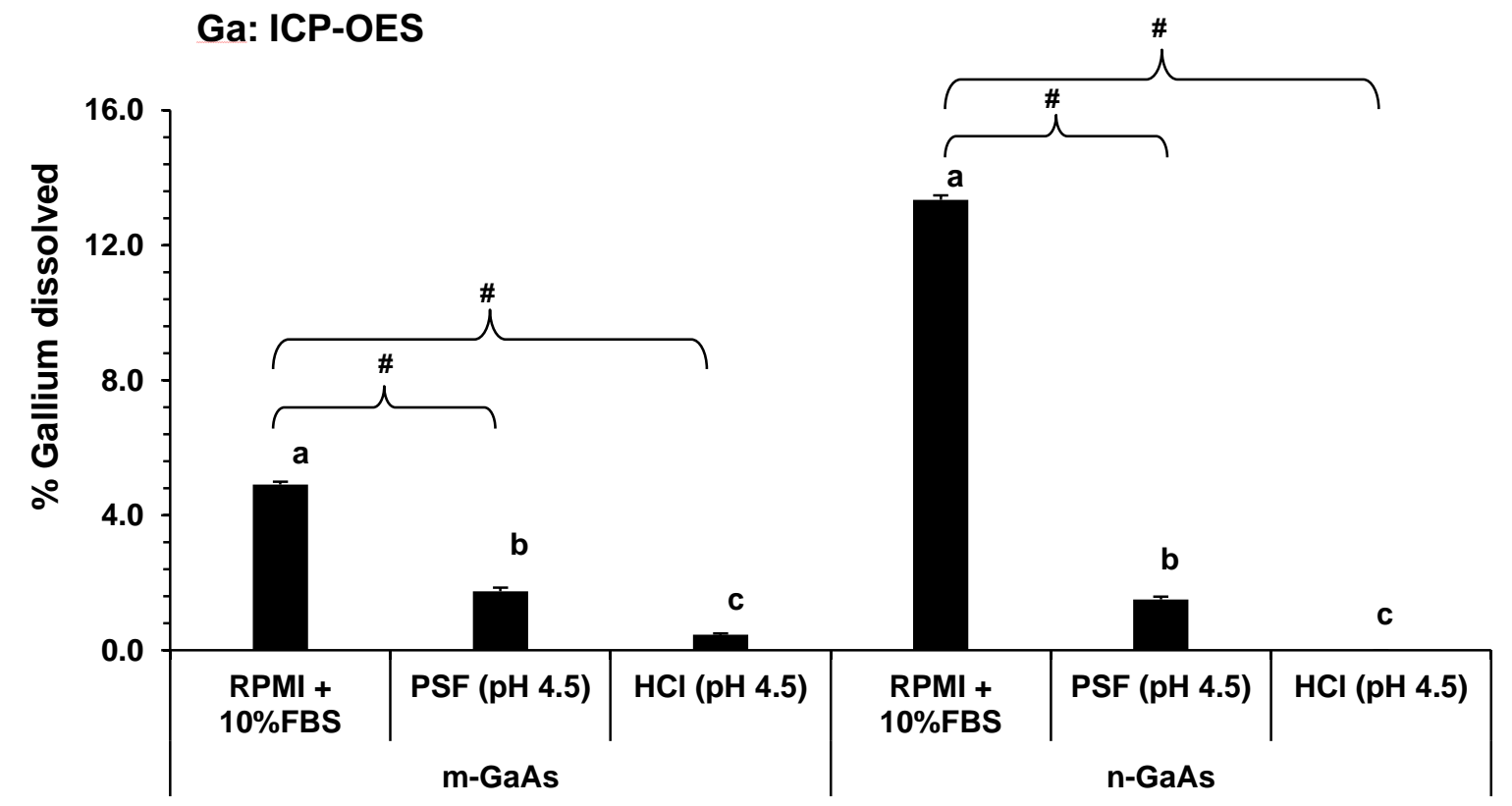

Figure S6. (A) ICP-OES analysis of Ga dissolution from micron- and nano-sized GaAs particles, which were incubated in neutral and acidic ( $\mathrm{pH} 4.5)$ media ( $\mathrm{PSF}$ and $\mathrm{HCl})$ at $24 \mathrm{~h}$. (\#) p<0.05: (a, b, c) comparing m-GaAs to n-GaAs in RPMI, PSF and $\mathrm{HCl}$, separately. 


\section{A THP-1: ATP assay at $24 \mathrm{~h}$}

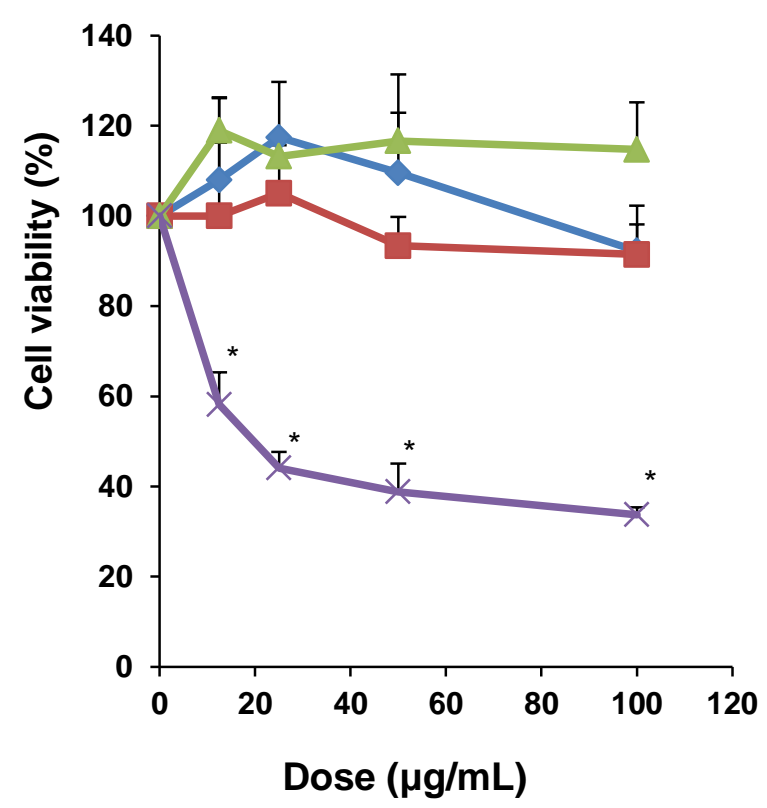

\section{THP-1: ATP assay at $72 \mathrm{~h}$}

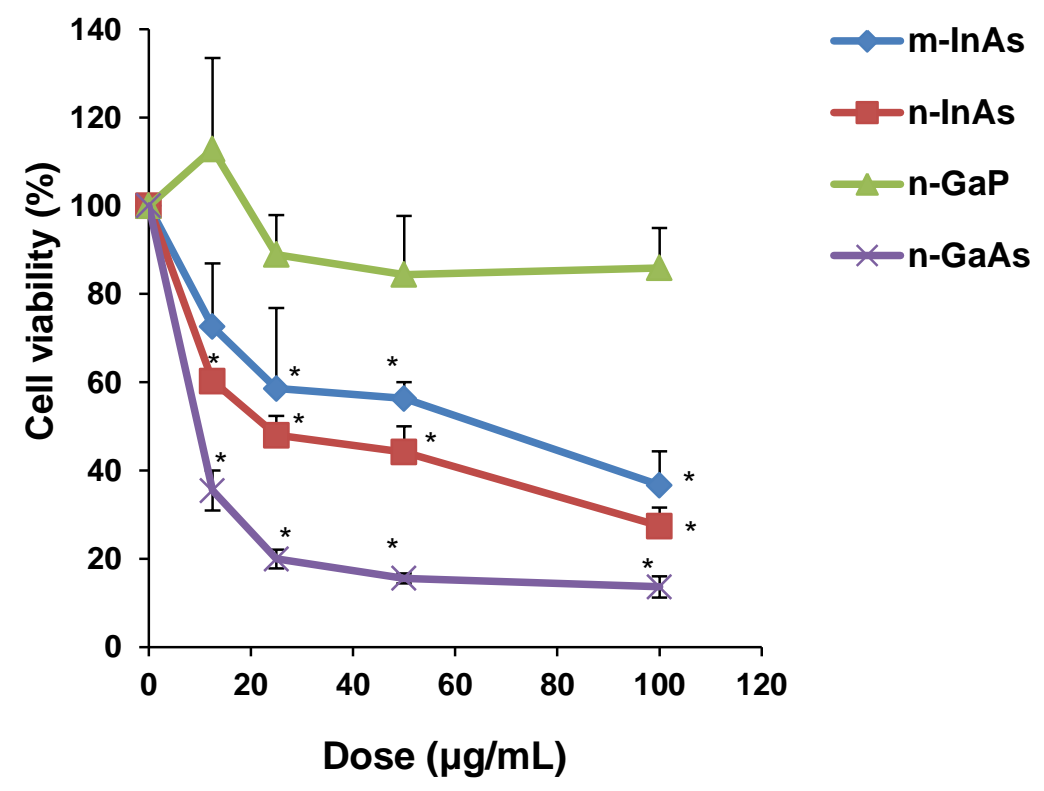

Figure S7. Assessment of THP-1 cell viability by the ATP assay plotted by mass dose. m-InAs, $\mathrm{n}$-InAs, $\mathrm{n}-\mathrm{GaP}$ and $\mathrm{n}-\mathrm{GaAs}$ particles, suspended in cell culture medium at $12.5-100 \mu \mathrm{g} / \mathrm{mL}$, were used to expose THP-1 for (A) 24 h, (B) 48 h, and (C) 72 h. (*) p<0.05 compared to control; (\#) $\mathrm{p}<0.05$, comparing $\mathrm{n}$-InAs to $\mathrm{m}$-InAs at the same dose. 


\section{A}
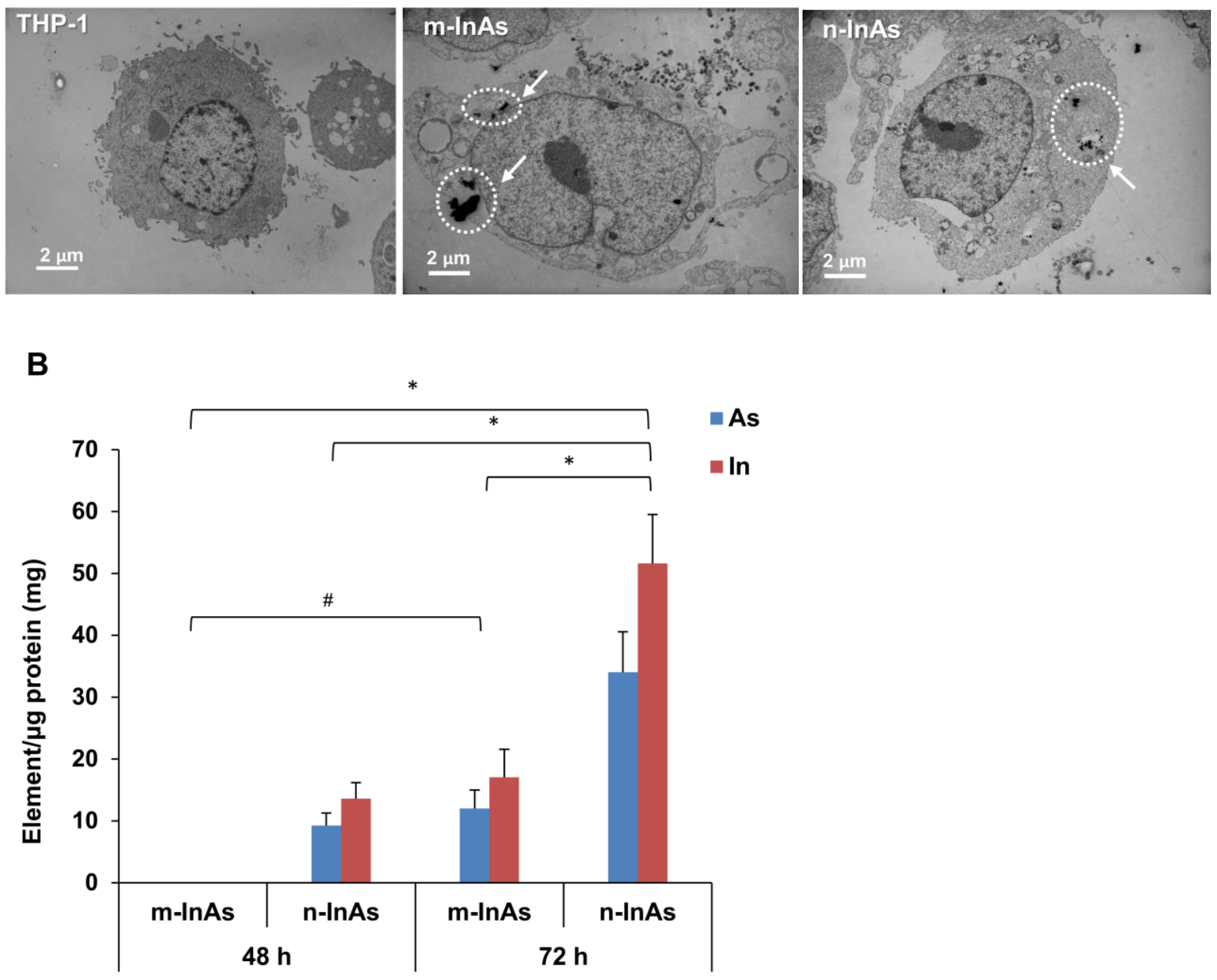

Figure S8. (A) TEM analysis to demonstrate cellular uptake and subcellular localization of InAs particles in THP-1 cells. The cells were treated with $50 \mu \mathrm{g} / \mathrm{mL}$ particles for $24 \mathrm{~h}$, then fixed and stained to prepare TEM grids. The images were taken with a JEOL 100CX electron microscope at $80 \mathrm{kV}$. The scale bar is $2 \mu \mathrm{m}$. (B) Use of ICP-OES to quantify the cellular In and As content in THP-1 cells incubated with different InAs particle sizes at 48 and $72 \mathrm{~h}$. $\left(^{*}\right) \mathrm{p}<0.05$, comparing to $\mathrm{n}$-InAs at $72 \mathrm{~h}$ in both As and In content. (\#) $\mathrm{p}<0.05$, comparing m-InAs at $48 \mathrm{~h}$ to $72 \mathrm{~h}$ in both As and In content. 